\title{
FPIPHYTIC ORCHIDS A SERIOUS PEST ON CITRUS TREES
} E

\author{
MEsvilite T. COOK
}

Epiphytic orchids have been frequently reported as growing on citrus trees but the writer does not know of any record of their occurring in sufficient abundance to be destructive. In July 1925, the attention of the writer was called to a citrus plantation between the Carolina Road and Trujillo Alto in which orchids have appeared in such great abundance as to be very destructive. Since that time other cases have been reported.

Two different species of orchid (Ionopsis utricularioides (Sw.) Tindl. and Leochilus labiatus Kuntze.) were found to be active agents in killing the branches of the trees, but $I$. utricularioides was by far of the greatest importance. Therefore, the greater part of this paper will be devoted to his species. The largest of these plants (Fig. 1) did not have more than six leaves, the largest leaf was nine inches in length and the longest fiower shoot was about two feet in length. However, the plants begin, blooming when very small. Many plants with leaves a little more than one inch in length produced flower shoots about four inches in length and a few flowers. The roots varied from a few in number to thick masses. A young plant (Fig. 2) is usually supported by three or four roots which grow in any direction for a distance of three or four feet or even more but adhere closely to the host plant. These roots branch rather sparingly, but as the plant increases in size and age new roots are produced which mingle with rents of other plants until the branch is almost completely encrusted for a considerable distance (Fig. 3). As the plants increase in age aerial roots (Figs. 4 and 5 ) are produced in very great abundance. These aerial roots frequently become attached to neighboring branches and are produced in such great abundance as to give the appearance of a mass of Florida Mloss. The aerial roots are not different from those attached to the branches. They are aerial simply because they have not come in contact with any resistant object. If one of these roots comes in contact with a stem or leaf within a reasonable time, they immediately become attached. They frequently become attached to the leaves of the orchid from which they were developed. 
The infections vary from a single small plant to dense masses of plants of various ages and sizes. The writer counted as many as twenty plants within a distance of twelve inches. The plants were also found clustered in masses (Fig. 5). A careful examination indicated that these plants came from seeds. When carefully dissected out, it was evident that each plant had its own root system. This had to be determined almost entirely from the study of very small plants because plants of one inch in length usually produced such lengthy root systems that it was difficult to follow them.: The encrustation of roots on the surface of a branch afiorded a most excellent place for the lodgement of seeds and thus gave rise to the great number of plants of various ages and sizes within a small area. The writer failed to find a single case in which two plants had a united root system. The roots when dry are very grey but many of them develop a light green color when young and in the presence of moisture.

The infections are most abundant in reduced sunlight and moisture but none were found in dense shade and excessive moisture. The infections usually start by the development of one or more seedlings on a branch or twig where it is well shaded. When the plant is ready to produce fruit, the flowering shoots grow upwards and into the sunlight. Small plants, producing short flowering shoots previously referred to are usually exposed to the sun as a result of the dying of the leaves of the host. The larger plants produce longer flowering shoots and more flowers, the flowering shoots always carrying the flowers into the sunlight. Although the plants start and develop in the shade and are seldom exposed to the direct sun light, except as a result of the dying of the leaves of the host, the flowers are always borne in the direct sunlight. It, therefore, appears that the strong sunlight may stimulate flowering. The plants fruit very freely and produce enormous numbers of very small seeds. These seeds are so small and light that they are easily carried by the wind to the same or neighboring trees, where some few of them germinate and give rise to new plants. Naturally the greater the distance from the point of origin the more scattered the new infections. It was very easy to locate these original infections and to trace the new infections from these centers.

The effects of the Orchids on the host plant was that of strangulation (Figs. 2-6). The roots grow very rapidly and inerease with the number and age of the plants and practically cover the entire surface of the branch for a considerable distance. The infected 
branches were eventually killed. Sometimes branches as much as three inches in diameter were killed. The killing of these branches ver'y naturally destroyed the symmetry of the trees, gradually weakened them, reduced production and eventually killed them. Th: rapid spread of this pest was a surprise to the writer, who visited this plantation thirteen months previous to the discovery of this cutbreak.

L. labiatus (Fig's. 7 and 8 ) is a very much smaller plant, was much less abundant and much less destructive. There was no cvidence that any branches more than three-fourths of an inch in: diameter had been killed by this species. It appeared that this species was more tolerant to sunlight than $I$. utricularioides.

\section{CONTROI,}

The control of these pests is comparatively simple. It consists in the removal of the plants so far as possible and in some cases the removal of heavily infected branches. Since the plants always start from seeds and not from the branching root systems, it is not necessary to remove all the roots. It is advisable to take the above precautions previous to spraying the trees, since the spraying fluids may kill some of the seeds and some of the very small plants which have been overlooked.

\section{EXPLANATION OF PLATES}

Figure 1: Ionopsis utricularioides, showing flowers, seeds pods and roots attached to the plant from which they were developed.

Figure 2: Young plants on a grapefruit branch.

Figure 3: Numerous small plants with well-advanced root systems on a grapefuit branch.

Figure 4: A number of plants on a dead branch. Also shows aerial roots.

Figure 5: Same as 4 .

Figure 6: A number of young plants on a branch which is still alive.

Figures 7 and 8: L. labiatus. 
$\$$ THE JOURNAL OF THE DEPARTMJNT OF AGRICULTURE
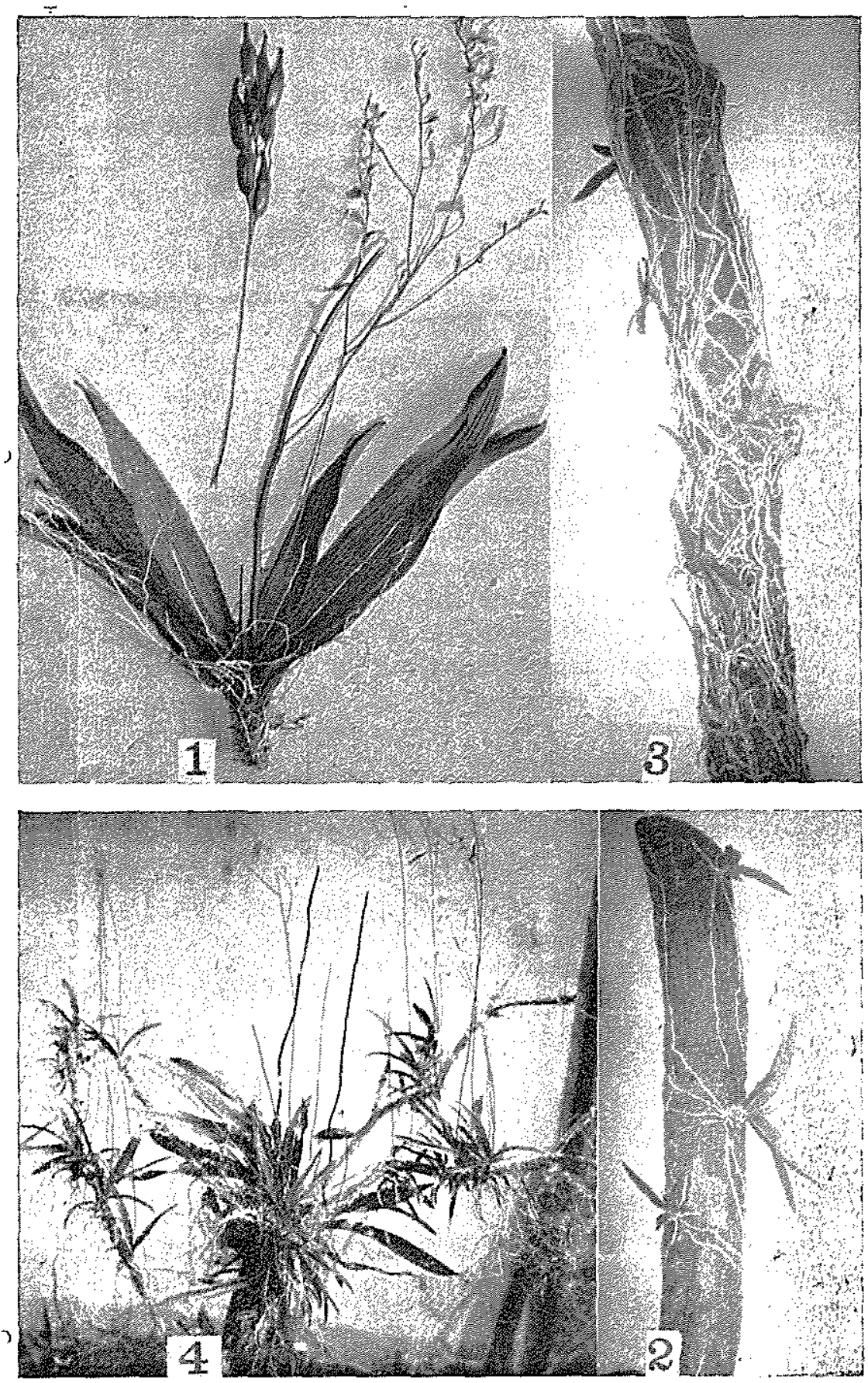

Flit it: 1.-lonophis triculariotdes, showint flowers, seed pods and roots attached to the seed plants from which they were devioped. 

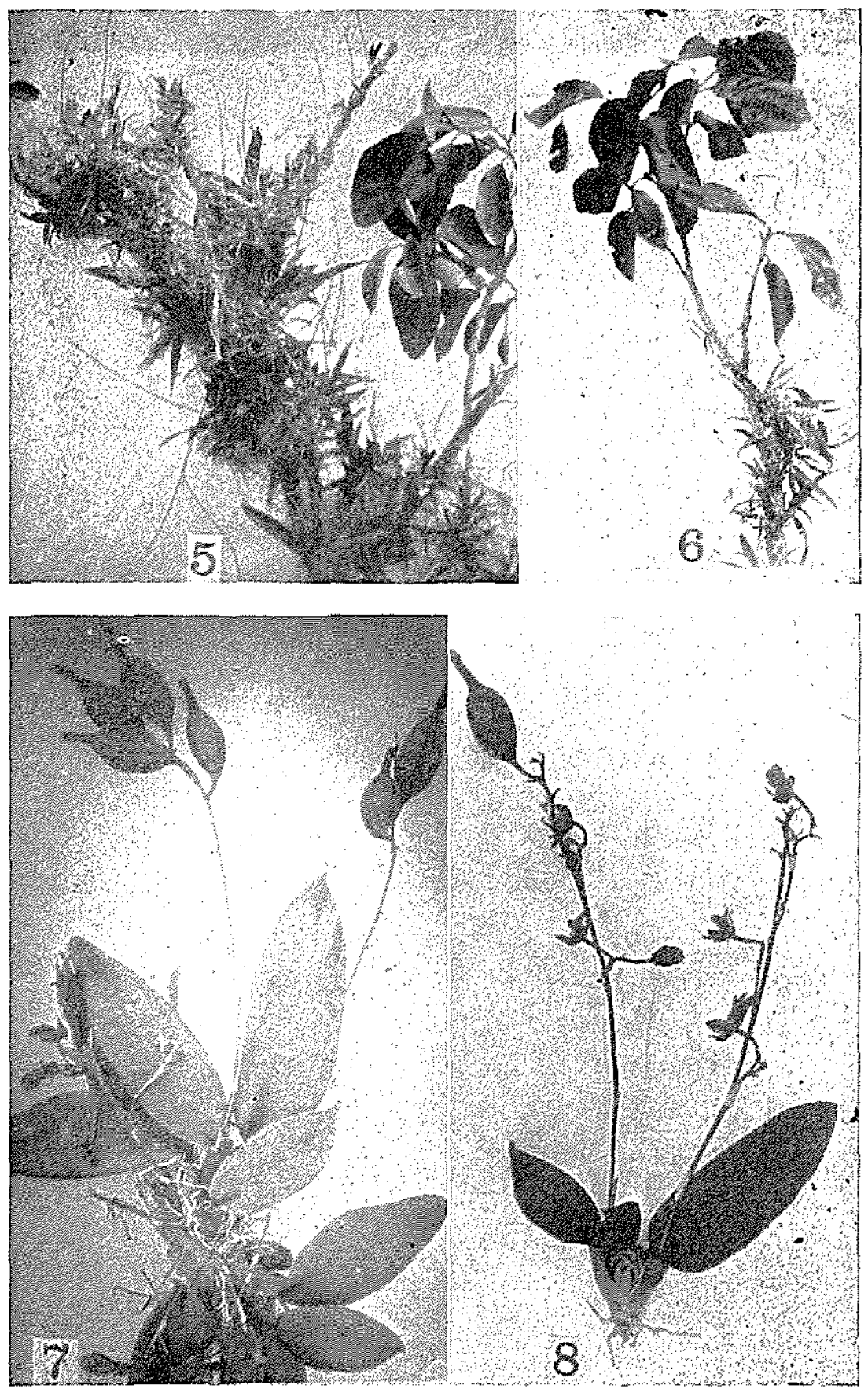

FIGt RE 5.-Same at: 4 .

FrGCRF 6.- number of young plants on a branch which is still alive.

Figl'ins 7 aND $8,-L$. laliatus. 